\title{
Possibilidades Filosóficas em Etnomatemática
}

\author{
Philosophical Possibilities in Ethnomathematics
}

\begin{abstract}
Resumo
Este artigo propõe-se a apresentar os principais resultados de uma pesquisa de mestrado que buscou investigar possibilidades filosóficas em Etnomatemática. A metodologia utilizada teve como base o conceito de cartografia proposto por Deleuze e Guattari, o qual possibilitou percorrer diferentes territórios - Filosofia; Educação Matemática; Matemática; Etnomatemática - e, posteriormente, esboçar prováveis mapas para o campo filosófico da Etnomatemática. Dentro deste contexto observaram-se alguns entrelaçamentos filosóficos que apontam aproximações com os pensamentos do filósofo da suspeita de Nietzsche. Assume-se, com base nas possibilidades filosóficas observadas na pesquisa, que o pensamento nietzschiano se configura como uma potencialidade para fundamentar o campo filosófico da Etnomatemática. É proposta uma reavaliação de algumas verdades deste território, colocando em suspeita certas crenças compartilhadas no campo próprio de produção das pesquisas da Etnomatemática. Este trabalho pretende contribuir, no campo da Educação Matemática, para o debate filosófico em Etnomatemática.
\end{abstract}

Palavras-chave: Etnomatemática. Investigação Filosófica. Cartografia. Nietzsche. Arte Trágica.

\begin{abstract}
This article proposes to present the main results of a Master's research that investigated the philosophical possibilities in Ethnomathematics. The methodology used was based on the mapping concept proposed by Deleuze and Guattari, which enabled traverse different territories - Philosophy; Mathematics Education; Mathematics; Ethnomathematics - and then outline maps likely to the philosophical field of Ethnomathematics. Within this context, there has been some philosophical twists that link with the thoughts of the philosopher of suspicion: Nietzsche. It is assumed, based on the philosophical possibilities observed in the survey, that Nietzsche's thought is configured as a capability to support the philosophical field of Ethnomathematics. We propose a reassessment of some of the truths of this territory, placing suspicion on certain beliefs shared in the production of research of Ethnomathematics own field. This work intends to contribute in the field of mathematics education and to the philosophical debate on Ethnomathematics.
\end{abstract}

Keywords: Ethnomatematics. Philosophical Inquiry. Cartography. Nietzsche. Tragic Art.

\footnotetext{
"Mestre em Educação pela Universidade Federal Fluminense (UFF). Doutorando do Programa de PósGraduação em Educação da Universidade Federal Fluminense (UFF), Niterói/RJ. Rua Prof. Marcos Valdemar Freitas Reis, s/n - Campus Gragoatá, Bloco D, sala 514 - Cep.: 24210-201 Niterói - RJ - Brasil. E-mail: fabiolen@gmail.com.

${ }^{* *}$ Doutora em Educação pela Universidade de São Paulo (USP). Professora do Programa de Pós-Graduação em Educação da Universidade Federal Fluminense (UFF). Rua Prof. Marcos Valdemar Freitas Reis, s/n - Campus Gragoatá, Bloco D, sala 514 - Cep.: 24210-201 Niterói - RJ - Brasil. E-mail: mcfantinato@gmail.com
} 


\section{Introdução}

Este artigo é fruto das muitas observações e indagações construídas na dissertação de mestrado do primeiro autor, tendo sido orientado pela segunda autora deste trabalho. A pesquisa realizada foi uma tentativa de analisar criticamente a problemática da construção filosófica da Etnomatemática em busca de possibilidades filosóficas para este campo de pesquisas.

O trabalho procurou instaurar novas reflexões sobre os pressupostos da Etnomatemática, apontando possíveis mapas filosóficos para esta área de estudos e pesquisas. Destacou-se neste sentido, em especial, uma aproximação com o pensamento de Nietzsche. Alguns dos objetivos perseguidos na investigação foram: apontar alguns dos pressupostos da Etnomatemática e, a partir disso, indicar possíveis mapas filosóficos para este campo; repensar algumas das verdades aceitas pela Etnomatemática a partir da fundamentação filosófica sugerida.

A metodologia empregada na pesquisa teve como base o método cartográfico proposto por Deleuze-Guattari (2000) e as pistas para o método indicadas por Passos, Kastrup e Escóssia (2009). O trabalho assumiu, seguindo esta metodologia, um caráter parcial, temporário e contextual, ou seja, não teve a pretensão de ser uma etapa final para qualquer tipo de inquietação assim como não buscou apresentar respostas absolutas ou definitivas a qualquer pergunta estabelecida. Por outro lado, tentou-se propor novos pensamentos e reflexões para as questões que se apresentavam na investigação.

Existem crenças compartilhadas pelos pesquisadores do campo etnomatemático que influenciam as bases de orientação filosófica da Etnomatemática? Amâncio (2004), por exemplo, compreende que existe um "princípio" da universalidade sociológica do conhecimento matemático assim como uma "essência" que caracteriza o Programa Etnomatemática na perspectiva d'ambrosiana. Observe-se o trecho a seguir:

Em todas as civilizações há alguma forma de matemática. As ideias matemáticas comparecem em toda a evolução da humanidade, definindo estratégias de ação para lidar com o ambiente, criando e desenhando instrumentos para esse fim, e buscando explicações sobre os fatos e fenômenos da natureza e para a própria existência (D’Ambrosio, 1999, p.97).

Neste sentido, destacam-se os apontamentos de Pais (2012) que, ao tratar de certos aspectos problemáticos das investigações em Etnomatemática, afirma que, mesmo existindo divergências entre os campos da Matemática e da Etnomatemática, "existe uma dimensão na 
qual ambos, matemáticos e etnomatemáticos, estão de acordo: a matemática está em todo o lado" (Pais, 2012, p.34).

Destacamos também, observando a produção acadêmica da área, a existência de posições filosóficas aparentemente contrárias no campo da Etnomatemática, como, por exemplo, a aceitação (ou a não) de um caráter de imanência (ou transcendência) na construção dos conhecimentos matemáticos a partir da perspectiva investigativa da Etnomatemática. Para ilustrar tal dualidade destacamos alguns entendimentos correntes sobre a posição dos pesquisadores etnomatemáticos (Vilela, 2013; Clareto, 2009, Knijniki, 2012; Ferreira, 2005; D’Ambrosio, 2011) diante do conhecimento matemático.

Pode-se assumir, por exemplo, que a Etnomatemática é uma região de crítica ao conhecimento matemático herdado da modernidade. As pesquisas etnomatemáticas adotam como base de orientação, nesta perspectiva, questionar a universalidade do conhecimento matemático assim como o seu caráter de transcendência (Knijnik, 2012, Vilela, 2013). Por outro lado, existem perspectivas que buscam investigar as experiências humanas que transcendem a experiência imediata e o conhecimento prático. Neste sentido, pode-se destacar o trabalho de Costa (2009). A proposta desta pesquisadora é assumir a possibilidade da construção do conhecimento matemático a partir dos mitos de grupos culturais específicos. Ela afirma que muitos estudos etnomatemáticos têm focalizado com maior ênfase questões de sobrevivência e trabalho, deixando de lado as "práticas sociais relacionadas à magia, às religiões, aos oráculos" (Costa, 2009, p.145). Segundo ela, as explicações que validam os saberes, nesta perspectiva, não se confundem com histórias fantasiosas ou contos de fadas, são entendidos "como explicações primeiras, engendradas pelos diferentes povos acerca do mundo, de si mesmos e das relações com o sagrado" (Costa, 2009, p.146).

A partir do que foi exposto, constatamos que em alguns casos os pesquisadores etnomatemáticos optam por separar a experiência e o entendimento humano em mundos dicotômicos (imanência/transcendência, metafísica/não metafísica) e, supostamente contraditórios. É oportuno pensar se existe uma possibilidade de reconciliação destes aspectos aparentemente opostos no campo etnomatemático. Assim, buscar pensamentos filosóficos que possam servir aos múltiplos caminhos das pesquisas desta área se mostrou de extrema importância na investigação desenvolvida. Este trabalho justifica-se, portanto, por representar uma tentativa de equilibrar as aparentes contradições deste campo de estudos e pesquisas e pelo desejo de contribuir com o debate filosófico que fundamenta a Etnomatemática. É uma tentativa de minimizar as incompreensões, equívocos e incertezas desta área e, ao mesmo tempo, de contribuir para a sua construção filosófica. 
Este artigo está organizado da seguinte forma: inicialmente apresenta-se o método cartográfico, em seguida destacam-se alguns pontos sobre a Etnomatemática, sua evolução histórica e algumas das ideias que emergem de suas pesquisas. E, por fim, observam-se algumas questões filosóficas presentes neste campo de pesquisa que apontam para possíveis entrelaçamentos com os pensamentos nietzschianos.

\section{Método cartográfico}

O conceito de cartografia pode ser encontrado no volume 1 da obra Mil platôs de Gilles Deleuze e Félix Guattari (2000). Na opinião de Gallo (2008), os conceitos na filosofia deleuzeana são ferramentas para fazer pensar, isto é, “aquilo que nos põe a pensar" (p.43). Assume-se neste trabalho a cartografia como ferramenta potente para construção de relações filosóficas em Etnomatemática.

Segundo aqueles filósofos, o modelo representativo arbóreo (no sentido cartesiano) no qual o conhecimento hierárquico se pauta, tem como principal finalidade a descrição de estados ou fatos. Para estes autores o conhecimento se assemelha muito mais a um "rizomacanal e seus mapas do que a uma árvore que 'articula e hierarquiza os decalques"”(DeleuzeGuattari, p.20, 2000). Nas palavras dos autores:

O mapa não reproduz um inconsciente fechado sobre ele mesmo, ele o constrói [...] O mapa é aberto, é conectável em todas as suas dimensões, desmontável, reversível, suscetível de receber modificações constantemente. Ele pode ser rasgado, revertido, adaptar-se a montagens de qualquer natureza (Ibidem, p.21)

Esta compreensão filosófica remete as múltiplas possibilidades para ver e construir mapas. O filósofo francês, além disso, "recusa toda a ideia de fatalidade decalcada" (p.21) e, neste sentido, entende que um rizoma é muito mais como aliança entre coisas (algo no meio do caminho, sem começo ou fim). A árvore, por outro lado é filiação, busca o fim e não se interessa pelo meio. Resumidamente, pode-se dizer que o modelo rizomático se opõe ao modelo da árvore (identificado pelos filósofos franceses como tradicional-cartesiano)

O rizoma assume formas diversas que caminham em todas as direções e sentidos, aceita os contrários, os paradoxos, o bom e o ruim simultaneamente; conecta qualquer ponto a qualquer outro e, com isso, coloca "em jogo regimes de signos diferentes" (p.14) em um mesmo território. Não é uma estrutura fixa, é mapa e não decalque (ou reprodução) ao infinito. Deleuze explica que o rizoma é formado por linhas, algumas de desterritorialização 
ou linhas de fuga $a^{\dagger}$. As linhas de fuga metamorfoseiam o território e proporcionam mudanças de estado ou natureza, se referem a mapas desmontáveis, modificáveis, com múltiplas entradas e saídas, podendo conduzir a direções insuspeitas. Contudo, cabe pontuar que, na perspectiva deleuzeana, o rizoma pode ser cartografado, acessando seu território por infinitos pontos que remetem a qualquer dos seu outros pontos, podendo conduzir a regiões inexploradas.

Para Deleuze os conceitos são produzidos não num plano de transcendência como ocorre com o conhecimento mítico-religioso, mas em um plano de imanência. E, neste sentido, Gallo (2008) comenta que "o plano de imanência é essencialmente um campo onde se produzem, circulam e se entrechocam os conceitos" (Gallo, 2008, p.44) ou, mais especificamente, ele "torna possível desenhar diagramas na cartografia do pensamento filosófico. O plano de imanência faz aparecer um rosto em meio a bruma da paisagem filosófica" (Ibidem, p.119). O território etnomatemático pode ser interpretado, neste contexto, como sendo constituído pela argamassa da imanência e pelas suas ferramentas de fazer pensar: os conceitos.

Ao optar-se por este caminho metodológico numa perspectiva filosófica, foi necessário ainda pensar em modos de articulação entre o método cartográfico e a pesquisa propriamente dita. Neste sentido encontramos Passos, Kastrup e Escóssia (2009) que apontam pistas para o método cartográfico. Segundo os autores, a cartografia como método é um acompanhamento de processos, ou, ainda, uma constante investigação do processo de produção do objeto investigado. É um método para experimentação que gera uma atitude investigativa que não abre mão do rigor exigido pela pesquisa, mas que a ressignifica. A cartografia é um método que impõe necessariamente uma intervenção no mundo, uma atitude política em seu sentido mais abrangente. A cartografia como método não sucumbe aos modelos prescritivos ou regras prontas, pois, na perspectiva destes autores, a pesquisa é uma intervenção da realidade que opera sobre a organização da realidade, transformando o mapa para conhecer o território enquanto o traça.

\footnotetext{
${ }^{1}$ Nossa interpretação dos conceitos deleuzeanos de desterritorialização e linha de fuga nascem dos indícios deixados pelo filósofo em seus textos. Entendemos que todo território realiza movimentos, deslocamentos, reconfigurações dinâmicas. Assumimos que desterritorialização é este movimento (criativo) que se realiza sobre o território, ou seja, é o que permite ultrapassar fronteiras e libertar o pensamento. Ponderamos que a desterritorialização também pode ser entendida, de maneira mais simples, como uma função de abandono do território. Notamos, ainda, que equivalente à desterritorialização é a operação, na cartografia, realizada pela linha de fuga. Um traçado que une dois pontos (ou dois conjuntos) do mapa, sem pertencer a nenhum dos dois, algo como um vetor que desorganiza a clausura das fronteiras rígidas.
} 
A Etnomatemática se apresenta, dentro desta perspectiva metodológica, como território-rizoma que possui diferentes dimensões. É possível, portanto, pensar em mapas da Etnomatemática - dinâmicos, fluidos, movediços - que emergem do método cartográfico.

\title{
3 As pesquisas em etnomatemática
}

Em 1984, no Quinto Congresso Internacional de Educação Matemática (ICME-5) D’Ambrosio realizou a palestra "Sócio-cultural Bases of Mathematics Education” na qual utilizou o termo Etnomatemática para expressar suas concepções e ideias acerca das questões socioetnoculturais associadas ao campo da Educação Matemática. Nascia oficialmente naquele momento, para o mundo acadêmico, a Etnomatemática como linha de estudos e pesquisas dentro da Educação Matemática. Desde então, a Etnomatemática tem sido considerada como uma tendência (Fiorentini, 1994, 1995), subárea ou vertente (D’Ambrosio, 2011; Knijnik, 2012) da Educação Matemática. E, mais que isso, tem sido apontada como um programa de estudos e pesquisas (D’Ambrosio, 2009) que tem como principal objetivo analisar os distintos modos de saber-fazer dos matemáticos - tais como contar, medir, comparar e classificar - de grupos culturais diversos. Sobre alguns dos pensamentos que influenciaram a Etnomatemática, Knijnik (2003) comenta:

\begin{abstract}
A vertente da Etnomatemática tem suas origens ligadas aos movimentos de Educação Popular que se desenvolviam na África e América Latina a partir da década de 60. A influência do pensamento de Paulo Freire no Brasil e outros países periféricos, apontando para a politicidade da Educação, sua não neutralidade e seu papel na construção de uma sociedade mais justa e igualitária também se fez sentir no âmbito da Educação Matemática (Frankenstein, 1987; Powell \& Frankenstein, 1992; D'Ambrosio, 1997). Ubiratan D'Ambrosio - o brasileiro reconhecido internacionalmente como aquele que cunhou a expressão Etnomatemática - teve como uma de suas marcas intelectuais as idéias de Freire sobre Educação (Freire, D’Ambrosio \& Mendonça, 1997; Higginson, 1997). Além disto foi grandemente influenciado em sua trajetória profissional por sua experiência como integrante de um projeto educativo da UNESCO que se desenvolvia em Mali, nos anos 70 (D'Ambrosio, 1993, D’Ambrosio e Ascher, 1994; Chassot \& Knijnik, 1997). (Knijnik, 2003, p.105 -106)
\end{abstract}

Os fatos destacados por Knijnik são corroborados em outros trabalhos do campo etnomatemático (Conrado, 2005; Gerdes, 1996). Com isso, pode-se assumir que a Etnomatemática começou a ser pensada durante as décadas de 60 e 70, mas que foi apenas na década de 80 que encontrou condições históricas e políticas favoráveis para emergir no cenário oficial dos centros acadêmicos. Destaca-se, colaborando com esta questão, as afirmações de D’Ambrosio. Segundo este pesquisador, foi a aceitabilidade do termo 
"Etnomatemática" em um evento internacional em 1977 que o encorajou a seguir adiante com sua proposta:

Em 1977, num Simpósio promovido pela American Association for the Advancement of Science, em Washington, DC, sobre Native American Science, reunindo especialistas de várias etno-ciências, aventurei-me a falar em etnomatemática. O nome foi aceito sem reservas e encorajou-me a usá-lo, porém não sem hesitação. Pareceu-me mais adequado evitar que a etnomatemática surgisse como uma outra disciplina. Mais apropriadamente, é tratá-la como um programa de pesquisa (D’Ambrosio, 2009).

O autor aponta sua preocupação em não tornar a Etnomatemática mais uma disciplina escolar, ou, ainda, como diria posteriormente, em aprisioná-la em uma gaiola epistemológica. Ele opta por instituir um programa de pesquisa a partir de sua inspiração em Irmes Lakatos (1922-1974), aceitando em seus fundamentos que a dinâmica cultural é intrínseca à construção de todo conhecimento.

Em 1996, Paulus Gerdes esboçou uma panorâmica geral da Etnomatemática até aquele momento. Ele comenta que a Etnomatemática, entendida como a Matemática de outras (sub) culturas, ou, ainda, como campo de investigação que aceita a existência de outras matemáticas culturalmente identificadas, surgiu tardiamente em relação às etnociências. Gerdes (1996) aponta para uma compreensão ampla da Etnomatemática como sendo um campo de pesquisas que busca estudar a Matemática (ou ideias matemáticas) em suas diferentes relações com a vida social e cultural. Este pesquisador elenca uma série de posturas e intenções dos investigadores da Etnomatemática que caracterizam, em sua opinião, as pesquisas da área. Algumas destas características seriam: a tentativa de contribuir para o reconhecimento das realizações matemáticas de outros povos (colonizados); a utilização de um conceito amplo de Matemática; a ênfase nas influências socioculturais no ensino e aprendizagem da Matemática; a construção de uma Educação Matemática crítica. E, em sua análise sobre a construção da Etnomatemática, afirma que a maioria das pesquisas tentava mostrar a existência das muitas matemáticas culturalmente construídas que se distanciavam da Matemática dominante (escolar e acadêmica).

Existe ainda um entendimento mais limitado da Etnomatemática como uma forma de Matemática de grupos étnicos. Contudo, de modo mais abrangente, destaca-se que as pesquisas em Etnomatemática estabelecem críticas a Matemática herdada da modernidade, ou seja, põem sob suspeita a posição da Matemática como a rainha das ciências, neutra e isenta de valores morais. Além disso, põe em dúvida o discurso que afirma que a linguagem da Matemática é universal e que suas verdades são eternas e inabaláveis (Vilela, 2013). Esta 
tendência no campo da Educação Matemática também contesta a imagem que associa a Matemática a uma entidade que está em toda a parte e cuja existência independe do homem.

D’Ambrosio (1997) aponta para a necessidade de se pensar criticamente a relação entre o colonialismo e a construção das verdades científicas, em particular da Matemática, presentes na história oficial. Ele afirma existir uma manipulação dessa história e sugere o programa de pesquisa em Etnomatemática como alternativa para enfrentar esta situação. Seguindo a indicação de D’Ambrosio, Knijnik (2012) utiliza a Etnomatemática como uma caixa de ferramentas teórica para questionar a noção de uma linguagem matemática universal pondo em suspeita tal universalidade.

Observa-se também que esta área de estudos e pesquisas tem passado por diferentes entendimentos, alguns anteriores ao ano de seu nascimento oficial no campo acadêmico. Gerdes (1996), por exemplo, elenca uma série de conceitos que emergiram nos debates a respeito da relação da Matemática com os contextos socioculturais. Paulatinamente, estes foram sendo incorporados e assimilados aos discursos da Etnomatemática, como, por exemplo: (1) Matemática oprimida (Gerdes, 1982); (2) Matemática não-padronizada (Carraher e outros, 1982; Gerdes, 1982,1985; Harris, 1987); (3) Matemática escondida ou congelada (Gerdes, 1982, 1985); (4) Matemática popular (Mellin-Olsen, 1986); (5) Matemática do povo (Julie, 1991); (6) Matemática codificada em saber-fazer (Ferreira, 1991); (7) Matemática implícita e não profissional (Ascher \& Ascher, 1981; Zaslavsky, 1994); (8) Matemática nativa (Gay\& Cole, 1967; Lancy, 1978); (9) Sociomatemática (Zaslavsky, 1973); (10) Matemática informal (Posner, 1978; 1982); (11) Matemática no ambiente socio-cultural (S. Doumbia, S. Touré, 1984); (12) Matemática espontânea (D`Ambrosio, 1982); (13) Matemática oral (Carraher e outros, 1982, Kane, 1987).

Observa-se, portanto, que a Etnomatemática se constitui um campo de investigação plural e de difícil identificação e definição. Destacam-se múltiplos entendimentos sobre a Etnomatemática (Barton, 2006; Gerdes, 1996; Miarka, 2011; Knijnik, 2012; D’Ambrosio, 2011). No entanto, percebe-se no campo das pesquisas uma predominância da perspectiva adotada pelo idealizador do Programa Etnomatemática Ubiratan D’Ambrosio (Knijnik, 2012; Breda, 2011; Miarka, 2011).

Diante desta pluralidade de entendimentos presentes em diferentes trabalhos da área, algumas questões podem ser formuladas: O que é Etnomatemática? Existe uma definição para Etnomatemática? O que caracteriza uma pesquisa em Etnomatemática? Quais os pressupostos filosóficos da Etnomatemática? Neste contexto, a busca por respostas a tais perguntas eventualmente podem conduzir a discursos contraditórios sobre a Etnomatemática, 
construindo uma aparência ilusória e ingênua a respeito deste campo de investigação. Como ultrapassar os limites da simples aparência fenomênica? Como traçar mapas em um território com paisagens tão múltiplas? Uma alternativa, nesta empreitada, aponta para a necessidade de observar as principais convergências e influências filosóficas no campo da Etnomatemática no Brasil.

\section{Inspirações filosóficas}

É possível, apesar da escassez de trabalhos da área voltados especificamente para as questões filosóficas (Fantinato, 2013; Costa, 2012), identificar alguns pensamentos filosóficos recorrentes na produção brasileira (dissertações, teses, artigos) em Etnomatemática. É possível ainda observar a presença mais acentuada de alguns personagens filosóficos neste campo de investigação.

A relativa importância atribuída à problemática da linguagem, dos discursos polissêmicos, dos valores socioculturais (morais) e da construção das verdades no processo de construção do conhecimento matemático, contribui como parâmetro de referência nesta etapa de busca de convergências.

Clareto (2003), por exemplo, toma de empréstimo os pensamentos de Nietzsche e Deleuze como a principais fontes de inspiração para seu trabalho no campo etnomatemático. A pesquisadora indica que a Etnomatemática surge em um momento pós-moderno de crítica ao conhecimento científico neutro e objetivo. Ela destaca que a Etnomatemática, na perspectiva d'ambrosiana busca "pensar o conhecimento para além das fronteiras rigidamente postas pela academia e pelos matemáticos" (Clareto, 2003, p.54).

Vilela (2013), por seu turno, se apropria dos pensamentos filosóficos do segundo Wittgenstein" numa tentativa de colocar a "linguagem como objeto de investigação" (Vilela, 2013, p.15) no campo da Educação Matemática numa perspectiva etnomatemática. Neste contexto de crítica aos pressupostos filosóficos presentes nos discursos e práticas matemáticas que, de modo geral, decorrem da modernidade, a pesquisadora defende que uma base teórica para Etnomatemática deve ter foco humanístico e aceitar a existência de matemáticas culturalmente diferentes.

Knijnik (2012), por sua vez, afirma que a partir da Etnomatemática foi possível questionar o conhecimento matemático hegemônico e buscar "outros modelos de

\footnotetext{
${ }^{2}$ Costuma-se falar em "segundo Wittgenstein" para fazer referência aos pensamentos da maturidade deste filósofo e presentes, em sua maioria, em sua obra Investigações Filosóficas.
} 
racionalidade" (Knijik, 2012, p.16). Em seu entendimento, a política do conhecimento dominante esconde ou marginaliza conteúdos e saberes, impedindo seu acesso aos currículos escolares. Ela afirma que a perspectiva etnomatemática, como uma "caixa de ferramentas teóricas" (Ibidem, p.28), em associação com a filosofia de Foucault, "possibilita analisar os discursos que instituem as matemáticas acadêmica e escolar e seus efeitos de verdade" (Ibidem, p.28). Além disso, a pesquisadora assume aproximações no campo filosófico com os pensamentos de Deleuze e, principalmente, do Wittgenstein (2009) das "Investigações Filosóficas".

Ferreira (2005) observa que alguns conceitos que atravessam as pesquisas etnomatemáticas merecem maior destaque, como, por exemplo: cultura, indivíduo, diálogo, desconstrução, transcendência, liberdade e interpretação. Nesse contexto, enfatiza que a temática cultural, com foco sobre os conceitos de identidade e Ser que foram fragmentados e abalados na pós-modernidade merecem ser repensados filosoficamente, pois, representam uma matriz paradigmática-filosófica para este campo. A fragmentação das limitações e barreiras de um mundo policiado, na perspectiva do pesquisador, permitiu aos sujeitos contemporâneos pós-modernos viver o dia (o instante presente), aproveitando o efêmero, o frívolo e o supérfluo em busca do gozo do agora. Neste sentido, o trágico se apresenta para o pesquisador como uma constante antropológica em que os sentimentos e prazeres superam a razão e a lógica.

Analisando os trabalhos acima e observando-se alguns termos e expressões recorrentes (multiculturalismo, pluralidade, diversidade, negação de universais, negação de fundamentos últimos, valorização de outros olhares, perspectivismo) nas pesquisas da área, foi possível estabelecer uma associação entre os pressupostos filosóficos da Etnomatemática com os pensamentos ditos pós-estruturalistas (Knijnik, 2009, 2012; Breda, 2011; Bello, 2010; Vilela, 2013; Clareto, 2009), ou ainda, como em alguns casos, pós modernos. Verifica-se neste caminho, na produção etnomatemática a partir da década de 90, uma forte influência dos pensamentos de Wittgenstein, Foucault, Deleuze e Nietzsche. Estes, no entanto, não são as únicas referências, mas, por outro lado, são as mais frequentes. Podemos citar, por exemplo, observando-se os primeiros momentos da construção teórica da Etnomatemática, a influência filosófica de Oswald Spengler (1880-1936), Irmes Lakatos (1922-1974) e Gaston Bachelard (1884-1962).

\section{Convergindo para Nietzsche}


A partir da análise realizada na pesquisa, foi possível observar uma relativa convergência para o pensamento filosófico nietzschiano. Dentro da perspectiva da investigação isto pode ser verificado ao se observar, por exemplo, a problemática da linguagem e das relações de poder associadas ao domínio de certos códigos, símbolos e discursos em Foucault (2011), Deleuze (2000) e Wittgenstein (2009).

Destaca-se, neste sentido, que a influência do pensamento de Nietzsche foi marcante para a filosofia francesa do período em que Foucault e Deleuze começaram a produzir seus trabalhos. Para estes filósofos foi um momento de encontro com a filosofia da suspeita e da crítica (Gallo, 2008).

Com relação a Wittgenstein (2009), pode-se considerar que a partir da pluralidade de significados dos termos e expressões, em seus jogos de linguagem, é possível contestar a ideia de uma verdade única e absoluta para a construção dos conhecimentos matemáticos. E, neste caso, acreditamos ser possível realizar uma aproximação com o pensamento nietzschiano a partir desta contestação. Além disso, as reflexões no campo da linguagem atravessam os pensamentos de todos os filósofos aqui considerados.

Dentro do território etnomatemático algumas linhas de fuga conduzem a um mapa filosófico de inspiração nietzschiana e, para apresentar alguns dos pensamentos do filósofo da suspeita, seguimos alguns dos apontamentos feitos por Deleuze (2001), Lefranc (2011), Machado (1984) e Marton (2008).

O filósofo alemão assume que tanto a verdade quanto o conhecimento científico têm como base valores morais, e estes devem ser interpretados e avaliados, para que possamos manter uma postura de critica diante das ilusões que emergem do campo científico. A vida em sua totalidade torna-se o maior critério de avaliação das verdades em Nietzsche. As ilusões que atravessam as verdades devem ser avaliadas de acordo com seu potencial para a vida, pois, na perspectiva nietzschiana, o mundo a ser decifrado e interpretado é ele mesmo uma interpretação.

Um dos caminhos apontados neste trabalho é, a partir de uma inspiração no pensamento filosófico nietzschiano, considerar a possibilidade de equilíbrio entre as forças apolínea e dionisíaca (metafísica e não metafísica - transcendente e imanente). Esta ideia é apresentada por Nietzsche (2011) em O Nascimento da Tragédia.

O apolíneo representa o ideal de beleza e perfeição na arte trágica grega. Apolo empresta à realidade um manto de ilusões para cobrir os horrores da vida. Ele representa uma força enganadora que visa encobrir o sofrimento, os fatos sensíveis da realidade e o mundo natural em sua contradição. O dionisíaco, por outro lado, é o aspecto cruel do mundo-vida, 
duro e ríspido. Dionísio vive intensamente a vida, embriagado e em êxtase incessante. Sem a ilusão do apolíneo o homem não suportaria os horrores da vida dionisíaca. A força apolínea adormece os sentidos do homem com um mundo de beleza aparente; é uma maneira de encobrir as atrocidades do mundo. A força dionisíaca se apresenta como balança desta ilusão. Uma força que encobre e a outra que expõe a realidade da vida. Uma impõe ordem e perfeição e a outra desorganiza e mostra o quão imperfeita é a existência humana. Uma mantém e a outra intensifica a vida. É uma experiência simultânea de lucidez e embriaguez. Esta comunhão de forças, a partir da arte trágica, possibilita que o homem compreenda a ilusão em que vive. Este equilíbrio é o que primeiramente nos propõe Nietzsche.

A interpretação filosófica de Nietzsche (associando arte, ciência, linguagem e moral) denuncia a decadência da arte em decorrência de uma ilusão metafísica a partir da filosofia socrático-platônica. Segundo ele, tal filosofia estabelece "a crença de que o conhecimento é capaz de pensar conscientemente na essência, na natureza, no fundo das coisas separando a verdade da aparência e considerando o erro como um mal” (Machado, 1984, p.37). Nietzsche, por outro lado, assume que os valores instituídos socialmente estão na base das verdades assumidas como dogmas pelos homens. Estas, por sua vez, são produzidos pela própria vida. É a vida que valora através dos homens. A vida, representada em sua crueza pelo dionisíaco, se configura como parâmetro de avaliação das verdades.

A partir desta perspectiva filosófica entende-se que o homem é capaz tanto de aceitar as ilusões que cria como também de reconhecer tais ilusões. É uma tentativa de equilibrar os conceitos paradoxais e opostos no campo filosófico (metafísico e não metafísico; imanência e transcendência) que se mostram a partir da linguagem, da construção das verdades, do conhecimento, das regras e normas dos diferentes grupos culturais. A verdade científica, na perspectiva nietzschiana, é uma invenção humana e que surge de uma necessidade ilusória de segurança. Esta ilusão é motivada pela fraqueza do homem diante da natureza. Para o filósofo, os homens são frágeis quando em comparação com as outras espécies e, além disso, desejam fugir do caos deste mundo-vida. Isso, para Nietzsche, se relaciona com uma interpretação moral dos fenômenos da natureza e da vida. Tais interpretações impõem valores superiores às verdades obtidas a partir da lógica e da razão.

Uma questão problemática e contraditória que pode surgir da adoção da filosofia nietzschiana está associada à comparação com seus pensamentos filosóficos em diferentes momentos de sua vida. Em seus trabalhos posteriores, o filósofo alemão aparentemente descarta a ideia de equilíbrio entre as forças apolínea e dionisíaca, posicionando-se apenas a favor da força dionisíaca (não metafísico). Existe uma compreensão de que Nietzsche 
descarta por completo a metafísica de seus pensamentos. Indicamos, no entanto, a possibilidade de perceber este equilíbrio nas obras posteriores do filósofo, como, por exemplo, quando ele fala metaforicamente em "O Viajante e sua Sombra", que "saberás que amo a sombra como a luz [...] a sombra é tão necessária quanto a luz" (Nietzsche, 2013, p.17$18)$.

As diferentes metáforas que remetem ao equilíbrio proposto em "O Nascimento da Tragédia" proliferam na obra deste filósofo, mas, paulatinamente aproximam-se mais da escuridão (Dionísio) que propriamente da luz (Apolo). Poder-se-ia argumentar, contudo, seguindo Heidegger (2007), que os conceitos nietzschianos ainda representam pensamentos metafísicos em seu conjunto, por toda sua obra. Esta é, no entanto, outra questão que não representa o foco desta pesquisa. Contudo, é necessário lembrar que o conceito de rizoma no método cartográfico deleuzeano permite a coexistência tanto de posicionamentos contrários quanto paradoxais. Nesta simultaneidade rizomática deleuzeana não faz sentido pensar em dicotomias ou hierarquias, mas, no máximo, em revezamentos. Observa-se, portanto, não apenas o consenso, mas também o dissenso.

Inspirados em Nietzsche, e com base no que foi exposto, não se tenta evitar o contraditório na investigação. Com isso em mente, estabelecemos a seguinte questão no desenrolar da pesquisa: $O$ que há de metafísico na Etnomatemática? Esta é uma pergunta que tem como principal objetivo questionar a crença em uma prevalência da imanência em detrimento da transcendência no campo filosófico da Etnomatemática. Supondo-se que a Etnomatemática se constrói em um plano de imanência (plano existencial, material e histórico) onde os conceitos etnomatemáticos são produzidos e se entrechocam, como descartar a existência de conceitos paradoxais e contraditórios neste plano? Desta reflexão e assumindo que existem direções insuspeitas no plano de imanência, surgem outras questões: metafísica e não metafísica, imanência e transcendência, podem estar simultaneamente e objetivamente presentes nas pesquisas deste território? Como pensar em transcendência e metafísica estando-se ancorado em um plano de imanência e não metafísica?

Talvez, possivelmente, a tendência em se buscar verdades universais e dogmáticas, próprio do pensamento acadêmico, principalmente matemático, tenha algum mérito nesta problemática. Não possuímos elementos que contribuam para solucionar estas questões ainda. No entanto, uma inspiração nietzschiana pode contribuir para se repensar as verdades aceitas implicitamente pela Etnomatemática, permitindo que as verdades fundamentais deste território sejam postas em suspeita. É preciso, seguindo o filósofo do perspectivismo crítico, 
refletir criticamente sobre as regras-dogmas e as ilusões que designam as verdades para este campo de pesquisa.

Podemos estabelecer algumas perguntas que exigem maiores investigações no território próprio da Etnomatemática: As pesquisas ou trabalhos etnomatemáticos, ao se afastarem de um tipo de conhecimento metafísico da Matemática, podem de alguma forma contribuir para desautorizar (ou não reconhecer) uma construção metafísica do conhecimento matemático de grupos culturais distintos? Estariam, por exemplo, negando a Matemática do grupo dos matemáticos? Como conciliar a valorização de outros olhares para a construção do conhecimento matemático em outras culturas e ao mesmo tempo negar a possibilidade das contradições (metafísica e não-metafísica)? Como analisar o valor atribuído à universalidade do conhecimento matemático, ou, pelo menos, de sua relativa permanência no campo científico? A crença na universalidade do conhecimento matemático como algo próprio da cultura humana, pode contribuir, dentro do discurso etnomatemático, para reforçar o caráter universalista e inabalável da Matemática?

Parece-nos relevante, portanto, tomando como base a filosofia de Nietzsche, observar de forma criteriosa algumas das verdades amalgamadas nas formas de vida tanto dos grupos culturais pesquisados pela Etnomatemática quanto do próprio grupo de pesquisadores deste campo. Este movimento não busca, inicialmente, negar valores ou práticas, mas sim repensálos criticamente no campo filosófico que está sendo construído para este território. Supomos, desta forma, ser possível aproximar as reflexões filosóficas da Etnomatemática dos contextos socioculturais de análise que emergem de suas pesquisas. Neste sentido, os debates sobre cultura, identidade e dominação política e econômica assumem relativo destaque.

A construção simbólica do campo cultural, seja pela linguagem ou pela imposição de valores e crenças, passa a direcionar as inquietações filosóficas que atravessam alguns dos pressupostos etnomatemáticos. Pode-se perguntar, por exemplo, que identidade cultural a Etnomatemática tenta valorizar e, mais que isso, o que entende por identidade cultural? Quais são os critérios de valorização cultural em que se apoiam os discursos etnomatemáticos? Como realiza tal valoração? Qual história não contada a Etnomatemática busca resgatar? Como a Etnomatemática institui novas histórias a partir das histórias silenciadas? Indiretamente as pesquisas etnomatemáticas estariam reforçando a existência das diferenças culturais? A partir da diferença eles e nós, imposta por alguns estudos etnomatemáticos, é possível que novas identidades estejam sendo construídas (Bampi, 2003; Breda, 2011; Bello, 2010) a partir da perspectiva etnomatemática? Uma fundamentação filosófica para 
Etnomatemática que se fortifica na imanência pode ser tão perigosa (ou frágil) quanto uma que se entrincheira exclusivamente na transcendência?

A Etnomatemática pode assim ser entendida como uma personagem entre tantos outros neste universo factual do mundo-vida. Ela habita o vasto território das pesquisas acadêmicas em Educação Matemática, mas, não apenas, pois caminha por muitos territórios deste palco. A Etnomatemática, porém, não é um único personagem, é múltiplo, possui diferentes máscaras e vestimentas. Não faz apenas monólogos, mas também busca estabelecer diálogos. O palco de suas apresentações não é fixo, está em constante mutação. Sua atuação e seu público não são os mesmos, apesar de ter elementos aparentemente repetidos e identificáveis a cada ato, cena ou peça.

A Etnomatemática pode ser considerada um Ser-no-mundo-vida que caminha sob a luz dos saberes das universidades, mas que não se furta de vagar pelas margens da sociedade, sob as sombras dos muros das academias. A Etnomatemática escapa do limite de sua caverna platônica (ou, se preferir, da sua gaiola epistemológica) esquivando-se dos raios de luz, observando as lições ensinadas pelas sombras em movimento. E, assim como Nietzsche, a Etnomatemática parece não rejeitar a luz, mas também não tenta negar as sombras. Ela não se resume aos ideais ou aos universais da Matemática acadêmica. A Etnomatemática busca ultrapassar os limites impostos pelo conhecimento hegemônico e oficial. Tenta reconciliar-se com as experiências mundanas do saber-fazer matemático.

Os mapas filosóficos traçados nesta pesquisa indicam alguns cenários possíveis para Etnomatemática. Existe, por exemplo, um mapa filosófico pós-crítico com ênfase na imanência e de oposição à metafísica (Vilela, 2013; Clareto, 2009). Existe, por outro lado, um mapa de transcendência e que aceita a possibilidade da metafísica. Destaca-se ainda um mapa etnomatemático d'ambrosiano (Breda e Lima, 2011) marcado profundamente pelas ideias deste pesquisador como, por exemplo, Amâncio (2004).

\section{Considerações finais}

As conclusões desta investigação são parciais, temporárias, contextuais e remetem às singularidades dentro do campo das pesquisas em Etnomatemática. Destacamos, no entanto, que a partir deste artigo, retomando algumas ideias desenvolvidas na dissertação de mestrado, foi possível aproximar a filosofia de Nietzsche da Etnomatemática e, em particular, propor novas reflexões para este campo. 
Indicamos que as pesquisas da Etnomatemática adotam, em sua grande maioria, uma postura de suspeita diante de um tipo de conhecimento matemático dito hegemônico (escolar/acadêmico) caracterizado pelo discurso ideológico da razão e pautado em uma compreensão metafísica desta disciplina matemática. Assume-se uma postura de abertura para lidar com a construção do conhecimento matemático pela adoção de diferentes parâmetros e, neste caso, busca-se ultrapassar certos limites impostos pela epistemologia tradicional. Neste sentido, a filosofia de Nietzsche e o campo filosófico da Etnomatemática podem ser articulados a partir da postura de crítica a um tipo de saber hegemônico, eurocêntrico, universal, neutro e absoluto, que silencia outras histórias e nega as diversas epistemologias culturalmente situadas.

Observamos ainda que certas questões conflituosas existem no campo filosófico da Etnomatemática, mas, em geral, são evitadas. Defende-se um posicionamento não metafísico e imanente para as pesquisas etnomatemáticas. Acreditamos, neste caso, ser relevante para a Etnomatemática repensar-se filosoficamente. Uma aproximação com os pensamentos de Nietzsche pode contribuir neste sentido, ao sugerir aos pesquisadores deste campo uma filosofia da suspeita (das crenças, verdades e valores). Uma filosofia que permita que pressupostos da própria área não se convertam em dogmas que aprisionem os pesquisadores deste território.

Destaca-se, por fim, que uma inspiração nietzschiana a partir de sua interpretação da arte trágica (grega), equilibrando o apolíneo e dionisíaco pode contribuir para se pensar a paradoxal e contraditória coexistência dos aspectos metafísicos e não metafísicos da produção do conhecimento matemático dentro do campo filosófico etnomatemático, principalmente quando em aproximação com as questões referentes à pluralidade da linguagem e da identidade (indivíduos ou grupos). Uma contribuição desta filosofia é, portanto, a possibilidade de se pensar em um mapa filosófico metafísico para a Etnomatemática.

\section{Referências}

AMÂNCIO, C. N. Da Universalidade. In: KNIJNIK, G.; WANDERER, F.; OLIVEIRA, C. J. (Org.). Etnomatemática, currículo e formação de professores. Santa Cruz do Sul: EDUNISC, 2004, p. 5369.

BAMPI, L. Governo etnomatemático: tecnologias do multiculturalismo. 2003. 200 f. Tese (Doutorado em Educação) - Faculdade de Educação, Programa de Pós-Graduação em Educação, Universidade Federal do Rio Grande do Sul, Porto Alegre, 2003.

BARTON, B. Dando Sentido à Etnomatemática: etnomatemática fazendo sentido. Tradução Maria Cecilia de Castello Branco Fantinato. In: DOMITE, M. do C.; RIBEIRO, J. P.; FERREIRA, R. (Org.). Etnomatemática: Papel, Valor e Significado. Porto Alegre, RS: Zouk, 2006. p. 39-74. 
BELLO, S. E. L. Etnomatemática: Uma analítica discursiva dos seus enunciados. In: ENCONTRO NACIONAL DE EDUCAÇÃO MATEMÁTICA Educação Matemática Cultura e Diversidade. 10., 2010, Salvador. Anais... Salvador, 2010. Disponível em: $<$ http://www. ufrgs.br/faced/educacaomatematica/Publicacoes/texto_xenem.PDF> Acesso em: 25 out. 2013.

BREDA, A. A Utilização da Etnomatemática nos Cursos de Formação Continuada de Professores: um Ensaio Analítico sobre a Produção de Subjetividades. 2011. 92 f., Dissertação (Mestrado em Educação em Ciências e Matemática) - Faculdade de Física, Programa de PósGraduação em Educação em Ciências e Matemática, Pontifícia Universidade Católica - PUC-RS, Porto Alegre, 2011.

BREDA, A.; LIMA, V. M. do R. Etnomatemática sob dois pontos de vista: a visão "D' Ambrosiana" e a visão Pós-Estruturalista. Revista Latinoamericana de Etnomatemática, Universidad de Nariño, Colômbia, v. 4, n. 2, p. 4- 31, janeiro, 2011.

CLARETO, S. M. Conhecimento, Inventividade e experiência: Potências do pensamento Etnomatemático. In: FANTINATO, M. C. (Org.). Etnomatemática, novos desafios teóricos e pedagógicos. Niterói: Editora da Universidade Federal Fluminense, 2009. p. 125-134.

CLARETO, S. M. Terceiras Margens: Um estudo etnomatemático de espacialidades em Laranjal do Jarí (Amapá). 2003. 254 f., Tese (Doutorado em Educação Matemática) - Instituto de Geociências e Ciências Exatas, Universidade Estadual Paulista, Rio Claro, 2003.

CONRADO, A. L. A Pesquisa Brasileira em Etnomatemática: desenvolvimento, perspectivas, desafios. 2005. 158 f., Dissertação (mestrado). Faculdade de Educação, Universidade de São Paulo, USP: São Paulo, 2005.

COSTA, W. N. G. No tecido/texto da Etnomatemática: Constituindo uma nova trama/linha de pesquisa. In: FANTINATO, M. C. (Org.). Etnomatemática, novos desafios teóricos e pedagógicos. Niterói: Editora da Universidade Federal Fluminense, 2009. p.143-153.

COSTA, W. N. G. Um espelho para a Etnomatemática: os artigos da área em periódicos nacionais de Educação Matemática. Revista Educação Matemática em foco, Campina Grande, v. 1, n. 1, p. 6581, jan./jun. 2012.

D’AMBROSIO, U. A História da Matemática: Questões Historiográficas e Políticas e Reflexos na Educação Matemática. In: BICUDO, M. A. V. (Org.). Pesquisa em Educação Matemática: Concepções \& Perspectivas. São Paulo: Editora UNESP, 1999. p. 97-115.

D'AMBROSIO, U. Ethnomathematics and its Place in the History and Pedagogy of Mathematics. In: FRANKENSTEIN, M.; POWELL, A. B. Ethnomatematics: Challenging Eurocentrism in Mathematics Education. Nova York: State University of New York Press, 1997. p. 13-24.

D’AMBROSIO, U. Etnomatemática: Elo Entre as Tradições e a Modernidade. 4. ed. Belo Horizonte: Ed. Autêntica, 2011.

DELEUZE, G.; GUATTARI, F. Mil Platôs. Rio de Janeiro: Ed. 34 Letras, 2000.

DELEUZE, G. Nietzsche e a filosofia. Porto, Portugal: Ed. Res, 2001. (Coleção Diagonal)

FANTINATO, M. C. Balanço da Produção Acadêmica dos Congressos Brasileiros de Etnomatemática. Revista Iberoamericana de Educación Matemática, Montevideo-Uruguai, v.1, n. 33, p.147-161, mar. 2013. 
FERREIRA, R. Educação Escolar Indígena e Etnomatemática: a Pluralidade de um Encontro na Tragédia Pós-Moderna. 2005. 245 f., Tese (Doutorado em Educação), Faculdade de Educação da Universidade de São Paulo, USP: São Paulo, 2005.

FIORENTINI, Dario. Rumos da pesquisa brasileira em educação matemática: o caso da produção científica em cursos de pós-graduação. Tese (Doutorado) Faculdade de Educação, Unicamp: Campinas, SP, 1994.

. Alguns modos de ver e conceber o ensino de matemática no Brasil. In: Zetetiké. Campinas. Ano 3, n.4, p. 1-37, 1995.

FOUCAULT, M. A ordem do discurso. Aula inaugural no collège de France, pronunciada em 2 de dezembro de 1970. 21. ed. São Paulo: Edições Loyola Jesuítas, 2011.

GALLO, S. Deleuze e educação. Belo horizonte: Autêntica, 2008.

GERDES, P. Etnomatemática e Educação Matemática: Um panorama geral. Revista Quadrante, Lisboa, v. 5, n. 2, p. 105-138, julho-dezembro, 1996.

HEIDEGGER, M. Nietzsche. São Paulo: Forense Universitária, 2007.

KNIJNIK, G. Pesquisa em etnomatemática: apontamentos sobre o tema. In: FANTINATO, M. C. (Org.). Etnomatemática, novos desafios teóricos e pedagógicos. Niterói: Editora da Universidade Federal Fluminense, 2009. p. 35-142.

KNIJNIK, G. Currículo, Etnomatemática e Educação Popular: um estudo em um assentamento do movimento sem terra. Currículo sem Fronteiras, UFRGS, Rio Grande do Sul, v. 3, n. 1, p. 96-110, jan./jun. 2003.

KNIJNIK, G. et al. Etnomatemática em movimento. Belo horizonte: Editora autêntica, 2012.

LEFRANC, J. Compreender Nietzsche. 6. Ed. Petrópolis, Rio de Janeiro: Editora Vozes, 2011.

MACHADO, R. Nietzsche e Verdade. Rio de Janeiro: Editora Rocco, 1984.

MARTON, S. Z. Nietzsche. In: PECORARO, R. (Org.). Os filósofos: Clássicos da filosofia. Rio de Janeiro: Vozes - PUC-Rio, 2008. p. 181-205.

MIARKA, R. Etnomatemática: do ôntico ao ontológico. 2011. 427 f., Tese (Doutorado em Educação Matemática) - Instituto de Geociências e Ciências Exatas, Universidade Estadual Paulista Júlio de Mesquita Filho, Rio Claro, 2011.

NIETZSCHE, F. O Nascimento da Tragédia. Tradução: Antônio Carlos Braga. São Paulo: Ed. Escala, 2011.

NIETZSCHE, F. O viajante e sua sombra. Tradução: Antônio Carlos Braga e Ciro Mioranza. São Paulo: Ed. Escala, 2013.

PAIS, A. A investigação em Etnomatemática e os limites da cultura. Revista Reflexão e Ação, Santa Cruz do Sul, v. 20, n. 2, p. 32-48, jul.-dez. 2012.

PASSOS, E.; KASTRUP, V.; ESCÓSSIA, L. Pistas do método da cartografia: pesquisa-intervenção e produção de subjetividade. Porto Alegra: Sulina, 2009. 
WITTGENSTEIN, L. Investigações filosóficas. Tradução Marcos G. Nontagnoli. 6. ed. Petrópolis, Rio de Janeiro: Editora Vozes, 2009. (Coleção Pensamento Humano)

VILELA, D. S. Usos e jogos de linguagem na Matemática: diálogo entre filosofia e educação matemática. São Paulo: Editora Livraria da Física, 2013. (Coleção contextos da ciência)

Submetido em Junho de 2014. Aprovado em Novembro de 2014. 